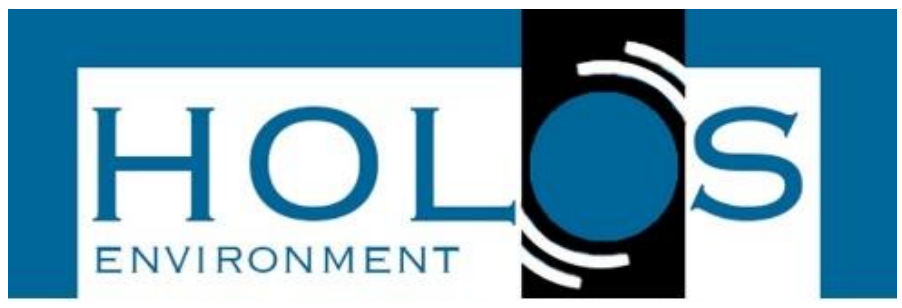

\title{
ESTUDO COMPARATIVO ENTRE MÉTODOS DE DIMENSIONAMENTO PARA RESERVATÓRIOS DE SISTEMAS DE APROVEITAMENTO DE ÁGUAS PLUVIAIS
}

\section{COMPARATIVE STUDY BETWEEN DESIGN METHODS FOR RESERVOIRS OF RAINWATER HARVESTING AND USE SYSTEMS}

\author{
Vitor Luís Amorim Fonseca ${ }^{1}$; Frederico Carlos Martins de Menezes Filho ${ }^{1}$
}

Artigo recebido em: 20/12/2018 e aceito para publicação em: 14/06/2019.

DOI: http://dx.doi.org/10.14295/holos.v19i2.12326

Resumo: $O$ desequilíbrio entre a demanda crescente por água nas diversas atividades humanas e a escassez pronunciada perfazem o panorama de uma crise hídrica nacional. Ações como a captação e o aproveitamento das águas pluviais mostram-se como uma alternativa para a escassez. Todavia, o dimensionamento do reservatório que compõe um Sistema de Aproveitamento de Águas Pluviais (SAAP), compreende uma etapa complexa, visto a existência de diversos métodos que resultam em volumes diferenciados entre si, consoante a NBR 15527 (ABNT, 2007), a saber: método de Rippl, método da simulação, método Azevedo Neto, método prático alemão, prático inglês e prático australiano. Desse modo, este trabalho objetiva comparar, para uma residência unifamiliar hipotética, os volumes calculados pelos métodos dispostos na referida norma e, também, pelo método apresentado por Dornelles (2012), para três capitais brasileiras: Belo Horizonte, Goiânia e Porto Alegre. De um modo geral, quanto aos métodos práticos e de Rippl, observa-se a discrepância entre os valores observados para os volumes calculados de reservatórios, variando de $4,89 \mathrm{~m}^{3}$ a $39,00 \mathrm{~m}^{3}$, para Belo Horizonte, por exemplo. O que, de fato, pode confundir a tomada de decisão pelo projetista, ressaltando, ainda, a limitação de tais métodos quanto ao desempenho do SAAP em seu tempo de uso. O método da simulação forneceu, para 15,00 m³ , a eficiência de 80,87\%, 80,81\% e 98,37\% para Belo Horizonte, Goiânia e Porto Alegre, respectivamente. Já utilizando o método proposto por Dornelles, em Belo Horizonte, o mesmo volume experimentará a eficiência de $87,80 \%$; para Goiânia a eficiência de $87,00 \%$ e; da mesma forma para Porto Alegre, $99,70 \%$. Comparando os dois últimos métodos, nota-se que não há grande diferença, podendo ser utilizados com segurança. Desse modo, os métodos da simulação e de Dornelles (2012) propiciaram valores mais seguros fornecendo os dados para análise dos índices de desempenho do SAAP no transcorrer dos anos.

Palavras-chave: Sustentabilidade. Recursos Hídricos. Águas de chuva. Cisternas.

Abstract: The imbalance between the increasing demand for water in the various human activities and the pronounced scarcity of water make up the panorama of a national water crisis. Actions such as the capture and use of rainwater are an alternative to scarcity. However, the design of the reservoir that integrates Rainwater Harvesting and Use system (RHUs), comprises a complex step, given the existence of several methods that result in differentiated volumes, according to NBR 15527 (ABNT, 2007), namely: Rippl method, simulation method, Azevedo Neto method, german practical method, practical English and practical Australian. In this way, this work aims to compare the volumes calculated by the methods established in the mentioned norm, and also by the method presented by Dornelles (2012), for three brazilian capitals: Belo Horizonte, Goiânia and Porto Alegre. In general, for the practical and Rippl methods, the discrepancy between the observed values for the calculated volumes of reservoirs, varying from $4,89 \mathrm{~m}^{3}$ to $39,00 \mathrm{~m}^{3}$, to Belo Horizonte, for example, is observed. This, in fact, may confuse decision making by the designer, also stressing the limitation of such methods on the performance of RHUs in

\footnotetext{
1 Universidade Federal de Viçosa (UFV), Campus de Rio Paranaíba Viçosa, MG. E-mails: (vitor.amorimcivil@gmail.com, menezesfilho.frederico@gmail.com)
} 
its time of use. The simulation method provided, for $15,00 \mathrm{~m}^{3}$, the efficiency of $80,87 \%, 80,81 \%$ and $98,37 \%$ for Belo Horizonte, Goiânia and Porto Alegre, respectively. Already using the method proposed by Dornelles, in Belo Horizonte, the same volume will experience the efficiency of $87,80 \%$; to Goiânia the efficiency of $87,00 \%$ and; in the same way for Porto Alegre, $99,70 \%$. Comparing the last two methods, it is noticed that there is not much difference, and can be used safely. Thus, the simulation and Dornelles (2012) methods provided safer values providing data for analysis of RHUs performance indices over the years.

Keywords: Sustainability. Water resources. Rainwater. Cisterns.

\section{INTRODUÇÃO}

\subsection{A escassez hídrica}

Consoante a Organização das Nações Unidas (ONU Brasil, 2015) há o aviso de que, até 2030 , a demanda mundial por água será $40 \%$ superior em relação à oferta. Conforme os dados publicados, 748 milhões de pessoas ainda não possuem acesso a fontes de água potável de qualidade e o crescimento populacional previsto para o ano de 2050 intensificará sobremaneira a demanda por água também em setores como agricultura e indústria.

Neste enfoque, conforme aponta Eliasson (2015), o crescimento populacional acentua a escassez hídrica, existindo a possibilidade, cada vez mais clara, de conflitos pela água. Além da importância da água relacionada à sobrevivência humana e o meio ambiente, Distefano e Kelly (2017) também destacam que a insuficiência da água pode ser um limite para o crescimento econômico dos países.

O crescimento populacional acarretou consequências que implicam no aumento da necessidade de água para o abastecimento, com a expansão da produção agrícola e a expansão na geração de indústrias (CUNHA et al., 2011). Desmatamentos, uso inadequado do solo, poluição e a degradação dos mananciais também se mostram, de acordo com Dantas e Sales (2009), como causadores da eminente escassez hídrica.

Com a finalidade de alterar essa realidade, Munhoz (2006) sugere o equilíbrio entre oferta e demanda de água visando a sustentabilidade como o princípio da orientação do desenvolvimento econômico e social. $\mathrm{O}$ autor ainda aborda que a potencialização das fontes alternativas ao abastecimento convencional, que não estão sob concessão dos órgãos públicos ou não sujeitas de cobrança pelo uso, configuram ponto determinante para alcançar esse objetivo. 
Nesta perspectiva, Hespanhol (2002), indica que a prática das fontes alternativas ao abastecimento convencional reserva as águas de melhor qualidade para usos nobres visto que utiliza a água de chuva, por exemplo, para finalidades não potáveis. Esta prática reserva a água que é fornecida pela companhia de abastecimento, diminuindo a tamanha pressão exercida nos mananciais hídricos.

Diante da situação de escassez dos recursos hídricos, Cunha et al. (2011) destacam que as medidas mais adotadas são o aproveitamento de águas pluviais e o reúso de águas cinza. Ambas práticas têm como premissa comum a conservação de água potável (CUBA E MANZANO, 2014; MAY, 2009; WANJIRU E XIA, 2018). Além do mais, existe a possibilidade de que estas técnicas e práticas sejam de baixo custo, indicadas às residências e, dessa maneira, estejam ao alcance da maioria da população e de fácil aplicação à rotina das pessoas, como proposto por Fonseca et al. (2018).

Em relação à captação e aproveitamento da água de chuva, Dornelles (2012) aponta três benefícios principais: econômicos, ambientais e à drenagem pluvial. $O$ retorno financeiro advém da redução do consumo de água fornecida pela concessionária, implicando na redução da conta. $O$ benefício ambiental surge da manutenção do ciclo hidrológico, pela redução da demanda de água potável, incidindo na conservação dos mananciais, dos seres vivos que dele dependem e a capacidade de autodepuração. Quanto à drenagem, ao se aproveitar as águas pluviais, haverá diminuição do volume que seria direcionado para esse sistema (DORNELLES, 2012).

\subsection{Métodos de cálculo para determinação do volume para armazenamento}

Consoante Leite (2017), o Sistema de Aproveitamento de Águas Pluviais (SAAP) constitui-se de elementos essenciais: a área de captação ou coleta, os condutores, o pré-tratamento, constituído, basicamente, por filtro e/ou reservatório de autolimpeza, e o reservatório de armazenamento, como é apresentado na Figura 1. 
Figura 1 - Sistema de aproveitamento de águas pluviais para uso permanente

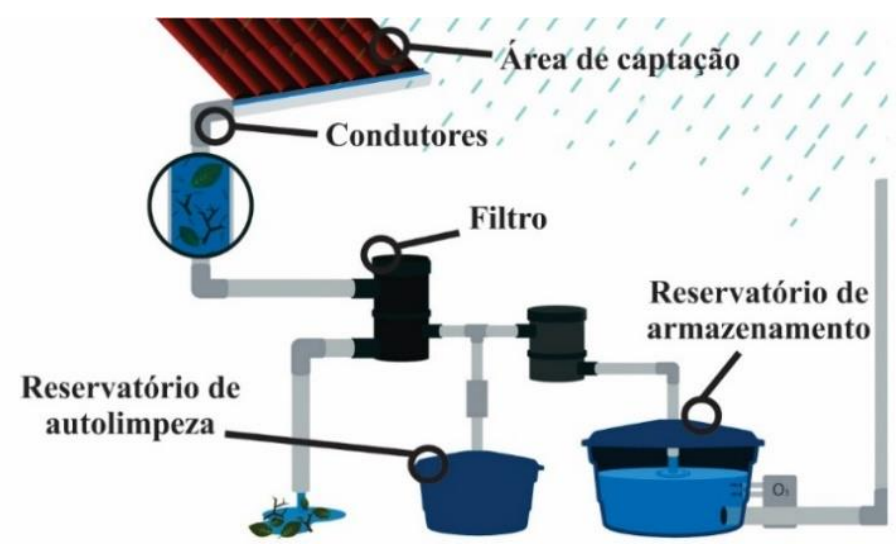

Fonte: Adaptado de IPT (2016)

De acordo com Cohim (2008) e Novakoski (2013), o reservatório de armazenamento representa a parte mais onerosa e complexa quanto ao dimensionamento.

Não há um padrão de método ou método único para a determinação do volume de armazenamento, consoante a NBR 15527 (ABNT, 2007) - "Água de chuva - Aproveitamento de coberturas em áreas urbanas para fins não potáveis - requisitos". A referida norma apresenta seis métodos diferentes, ficando a critério do projetista qual deles utilizar ou, ainda, dimensionar de uma outra forma, desde que devidamente justificado. São eles: método de Rippl, método da simulação, método Azevedo Neto, método prático alemão, método prático inglês e método prático australiano.

O método Azevedo Neto, prático alemão, prático inglês e prático australiano, os chamados métodos práticos, são determinados por equações empíricas. Já o método de Rippl e da simulação, chamados métodos de simulação, utilizam dados de forma a favorecer as variabilidades espaciais e temporais da chuva. Diante disso, nota-se que tais métodos não seguem uma regra comum, existindo a possibilidade de resultarem em volumes diferentes para o reservatório em uma mesma situação, fato que gera incertezas, principalmente, em relação à análise econômica do dimensionamento (DORNELLES, 2012; LEITE, 2017).

Neste enfoque, o referido trabalho objetiva comparar os volumes de reservatórios calculados por meio dos métodos apresentados pela NBR 15527 (ABNT, 2007) e pelo método apresentado por Dornelles (2012) para três capitais brasileiras com regimes de chuva distintos. 


\section{METODOLOGIA}

A metodologia proposta neste trabalho dividiu-se em sete etapas que são ilustradas no fluxograma da Figura 2. Estabeleceu-se, para a avaliação dos métodos de dimensionamento de reservatórios, uma residência familiar definindo-se três capitais brasileiras para o estudo. Com base nas séries históricas pluviométricas das capitais definidas e dos métodos de cálculo, procedeu-se ao dimensionamento dos reservatórios para cada uma das situações.

Figura 2- Fluxograma da metodologia

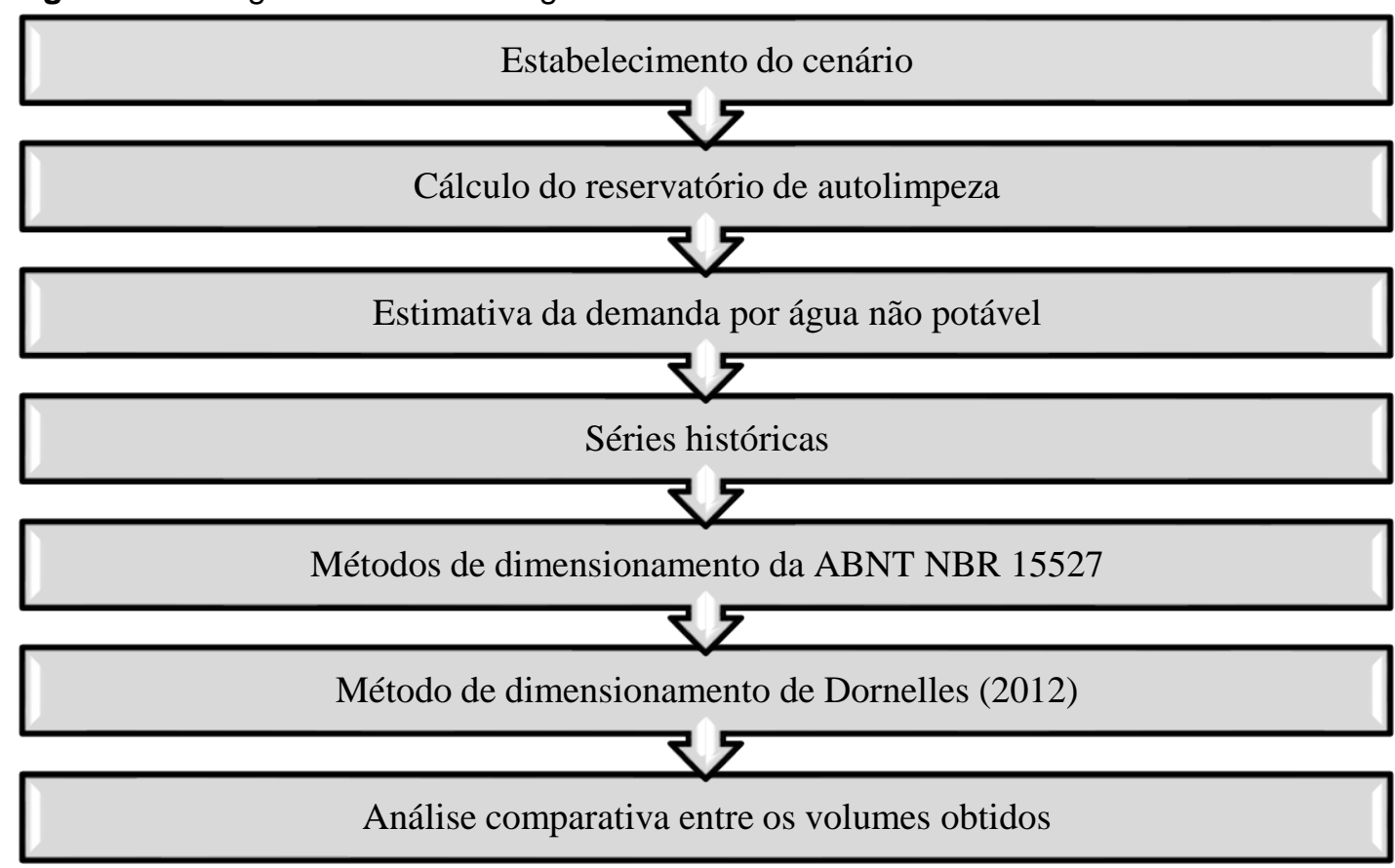

Fonte: Elaborado pelos autores

\subsection{Estabelecimento do cenário}

Com o objetivo de melhor comparar os métodos de cálculo para o dimensionamento do reservatório para um SAAP foram calculados os volumes para três capitais brasileiras: Belo Horizonte (MG), Goiânia (GO) e Porto Alegre (RS). Além disso, adotou-se uma residência familiar com as seguintes considerações: área de coleta de 150 m²; 4 moradores; $5 \mathrm{~m}^{2}$ de área de jardim/gramado e 1 automóvel.

Como não é possível coletar todo o volume que é precipitado, visto que pode ocorrer a evaporação e absorção da água pelo material componente do telhado durante os eventos de chuva, considerou-se nos cálculos do volume do reservatório, o 
coeficiente de escoamento superficial (C). Neste intuito, adotou-se, consoante Azevedo Netto et al. (1998), o valor de 0,95 para o C, considerando a superfície composta por telhados. Portanto, fatores como o tamanho da área e o material de que é feito o telhado são determinantes para a quantidade de água que pode ser captada e direcionada para o reservatório.

\subsection{Cálculo do reservatório de autolimpeza}

O cálculo do reservatório de autolimpeza baseou-se na NBR 15527 (ABNT, 2007) pela recomendação do descarte de $2 \mathrm{~mm}$ da chuva inicial. Como descrito no item anterior, com uma área de telhado de $150 \mathrm{~m}^{2}$, será necessário um reservatório de $0,30 \mathrm{~m}^{3}$ para que esse descarte seja efetuado após todo evento de chuva.

\subsection{Estimativa da demanda por água não potável}

De posse dos dados da residência familiar, definiu-se a quantidade de água da chuva que poderá ser utilizada, considerando fins não potáveis. Assim, considerou-se que a água advinda da concessionária de abastecimento poderá ser substituída pela água da chuva para uso externo em torneiras destinadas à irrigação de jardins e lavagem do carro e, para uso interno, nas descargas da bacia sanitária. Para tais estimativas foram utilizados parâmetros, propostos por Tomaz (2010), disponibilizados na Tabela 1.

Haja vista a situação do presente trabalho com 4 moradores, $5 \mathrm{~m}^{2}$ de jardim/gramado e 1 carro, a estimativa de demanda por água para a destinação em atividades não potáveis resulta em $6,79 \mathrm{~m}^{3} / \mathrm{mês}$.

Tabela 1 - Parâmetros de engenharia para estimativas da demanda residencial de água

\begin{tabular}{cccc} 
Tipo de uso & Descrição & Unidades & Valores \\
\hline Externo & Irrigação de gramado ou jardim & Litros/dia/m² & 2 \\
Externo & Lavagem de carros & Litros/lavagem/carro & 150 \\
Externo & Lavagem de carros: frequência & Lavagem $/$ mês & 4 \\
Interno & Descarga na bacia sanitária & Descarga/pessoa/dia & 5 \\
Interno & Volume de descarga & Litros/descarga & 5 \\
Interno & Vazamento bacias sanitárias & Percentagem & 9 \\
\hline
\end{tabular}

Fonte: Adaptado de Tomaz (2010) 


\subsection{Séries pluviométricas}

Os dados de séries históricas de precipitação para as capitais brasileiras escoIhidas, Belo Horizonte, Goiânia e Porto Alegre, foram obtidas através do portal Hidroweb (http://www.snirh.gov.br/hidroweb/publico/apresentacao.jsf), de responsabilidade da Agência Nacional de Águas (ANA). Na Tabela 2 são apresentadas as informações dos postos pluviométricos selecionados. É importante citar que os períodos de falhas, verificados apenas para Porto Alegre, foram preenchidos com os dados dos meses mais secos observados dentro do intervalo de tempo analisado de 30 anos.

Tabela 2 - Informações dos postos pluviométricos

\begin{tabular}{|c|c|c|c|}
\hline & Belo Horizonte & Goiânia & Porto Alegre \\
\hline $\begin{array}{l}\text { Posto pluvio- } \\
\text { métrico }\end{array}$ & Belo Horizonte (Horto) & Goiânia & Porto Alegre \\
\hline Código & 1943055 & 1649013 & 3051011 \\
\hline Tipo & Pluviométrica & Pluviométrica & Pluviométrica \\
\hline Responsável & $\begin{array}{l}\text { Instituto Nacional de } \\
\text { Meteorologia (INMET) }\end{array}$ & $\begin{array}{l}\text { Instituto Nacional de Me- } \\
\text { teorologia (INMET) }\end{array}$ & $\begin{array}{l}\text { Instituto Nacional } \\
\text { de Meteorologia } \\
\text { (INMET) }\end{array}$ \\
\hline Latitude sul & $19^{\circ} 54^{\prime} 00^{\prime \prime}$ & $16^{\circ} 40^{\prime} 00^{\prime \prime}$ & $30^{\circ} 03^{\prime} 00^{\prime \prime}$ \\
\hline $\begin{array}{l}\text { Longitude } \\
\text { oeste }\end{array}$ & $43^{\circ} 55^{\prime} 12^{\prime \prime}$ & $49^{\circ} 15^{\prime} 36^{\prime \prime}$ & 5110'12"' \\
\hline Período & $01 / 1987$ a $12 / 2016$ & 08/1986 a 09/2016 & $01 / 1987$ a $12 / 2016$ \\
\hline Falhas & Não & Não & Sim \\
\hline
\end{tabular}

Fonte: Elaborado pelos autores

\subsection{Métodos de dimensionamento consoante a NBR 15527 (ABNT, 2007)}

Como mencionado, a NBR 15527 (ABNT, 2007) apresenta seis diferentes métodos para o dimensionamento de um reservatório de armazenamento componente de um SAAP. Os métodos com as suas respectivas equações são apresentados na Tabela 3 e as observações acerca destes são apresentados a seguir. Recomenda-se que, para melhor esclarecimento sobre o uso dos métodos, seja consultada a referida norma. 
Tabela 3 - Métodos e equações da NBR 15527 (ABNT, 2007)

\begin{tabular}{cc}
\hline Métodos & Equação \\
\hline Método de Rippl & $\mathrm{S}_{(\mathrm{t})}=\mathrm{D}_{(\mathrm{t})}-\mathrm{Q}_{(\mathrm{t})}$ \\
Método da simulação & $\mathrm{S}_{(\mathrm{t})}=\mathrm{Q}_{(\mathrm{t})}+\mathrm{S}_{(\mathrm{t}-1)}-\mathrm{D}_{(\mathrm{t})}$ \\
Método de Azevedo Neto & $\mathrm{V}=0,042 \times \mathrm{P} \times \mathrm{A} \times \mathrm{T}$ \\
Método prático alemão & $\mathrm{V}=$ mínimo entre $(\mathrm{V} ; \mathrm{D}) \times 0,06$ \\
Método prático inglês & $\mathrm{V}=0,05 \times \mathrm{P} \times \mathrm{A}$ \\
Método prático australiano & $\mathrm{V}_{(\mathrm{t})}=\mathrm{V}_{(\mathrm{t}-1)}+\mathrm{Q}_{(\mathrm{t})}-\mathrm{D}_{(\mathrm{t})}$
\end{tabular}

Legenda: $\mathrm{S}(\mathrm{t})$ : volume de água no reservatório no tempo $\mathrm{t} ; \mathrm{D}(\mathrm{t})$ : demanda ou consumo no tempo $\mathrm{t}$; $\mathrm{Q}(\mathrm{t})$ : volume de chuva captada no tempo t; $\mathrm{S}(\mathrm{t}-1)$ : volume de água no reservatório no tempo t; $\mathrm{V}$ : volume de água do reservatório; $P$ : valor numérico de precipitação; $A$ : valor numérico da área de coleta, em projeção; $T$ : número de meses que confere o período de estiagem; $\mathrm{V}(\mathrm{t}-1)$ : volume de água que está no tanque no início do mês $\mathrm{t} ; \mathrm{V}(\mathrm{t})$ : volume de água que está no tanque no início do mês t. Fonte: Adaptado de ABNT (2007).

\subsubsection{Método de Rippl}

Segundo Giacchini (2016), o Método de Rippl, ou também chamado de Método do Diagrama das Massas, é amparado no fato de regularizar a vazão, ou seja, reservar a água em intervalos de tempos com chuvas mais intensas para utilizá-la na temporada de estiagem. O autor ainda salienta que este método é recomendado, portanto, em situações que tenham um período crítico muito bem determinado.

\subsubsection{Método da simulação}

Observa Dornelles (2012) que o Método de Rippl vem sendo substituído pelo Método da Simulação porque, este último, possibilita verificar a porcentagem de atendimento à demanda, ou eficiência, e, ainda, os níveis de extravasamento. O mesmo autor chama estes dois quesitos como "índices de desempenho", porque são determinantes para analisar a real potencialidade do sistema.

Amorim e Pereira (2008) apresentam o Método da Simulação como, basicamente, fixar o volume do reservatório e verificar os níveis de atendimento. Os níveis de atendimento à demanda, para Dornelles (2012), ou a eficiência do sistema, para Amorim e Pereira (2008) e Moruzzi e Oliveira (2010), representam o intervalo de tempo que a demanda por água pluvial é suprida pelo volume captado no reservatório. Tal parâmetro pode ser calculado por meio da Equação 1, conforme apresenta Moruzzi e Oliveira (2010). 
$E=1-\left(\frac{n}{N \times 365}\right)$

em que: $\mathrm{E}=$ eficiência ou atendimento à demanda (\%); $\mathrm{n}$ = número de dias em que o reservatório permanece ocioso; $\mathrm{N}$ = número de anos da série histórica observada.

Já a porcentagem de extravasamento é a relação entre o volume de água que foi extravasado e o volume de chuva diário produzido.

\subsubsection{Métodos de Azevedo Neto, prático alemão, prático inglês e prático australi- ano}

O método Azevedo Neto, prático alemão, prático inglês e prático australiano, abordados na NBR 15557 (ABNT, 2007), compreendem a utilização de equações empíricas (Tabela 3) sem apresentar informações sobre o embasamento teórico utilizado para a dedução das mesmas; tão quanto limitações de cada método e condições que oferecem melhores resultados. Isto dificulta a escolha do método, para o dimensionamento do reservatório de aproveitamento de águas pluviais, pelo projetista, já que os valores obtidos podem ser discrepantes entre si; para uma parte que representa o maior custo no sistema em pauta.

\section{6 Ábacos e tabelas para o dimensionamento do reservatório de um SAAP}

O método proposto por Dornelles (2012), tem como cerne o Método da simulação, a partir do qual construíram-se ábacos e tabelas, utilizando o método de Monte Carlo com a simulação do aproveitamento de água pluvial por séries sintéticas de precipitação (LEITE, 2017).

O processo para o uso dos ábacos e tabelas consiste num processo de 4 etapas, que dependem se o dimensionamento será feito para dimensionar um reservatório a ser construído ou para analisar o desempenho de uma cisterna com um volume já definido.

Para o primeiro caso, é necessário ter o conhecimento da área de coleta; fixar a demanda diária por água não potável; obter a relação entre a demanda pela área de captação e; adotar ou o extravasamento ou o nível de atendimento à demanda 
para que seja feita a análise dos índices de desempenho do reservatório que será implementado no SAAP (DORNELLES, 2012).

Caso o procedimento seja feito para analisar o desempenho de uma cisterna com um volume já definido, obtém-se o valor da área de captação; fixa-se o volume do reservatório existente; divide-se o volume pela área de captação e; da mesma maneira, adota-se um índice de desempenho para que seja feita o estudo (DORNELLES, 2012).

\subsection{Análise comparativa entre os volumes obtidos}

Tendo em vista os métodos de cálculo apresentados, o presente trabalho teve como procedimento inicial a determinação do volume do reservatório para armazenamento de água da chuva para os cenários descritos conforme os métodos de Rippl, em que foi utilizado médias mensais e diárias, e os métodos práticos: Azevedo Neto, prático alemão, prático inglês e prático australiano.

Como é necessário um valor pré-determinado de reservatório para o método da simulação, Carvalho, Oliveira e Moruzzi (2007) recomendam que os valores utilizados sejam arbitrados conforme outros métodos. Portanto, baseando-se nos valores encontrados para os volumes dos reservatórios utilizando os métodos práticos e de Rippl, foram atribuídos os volumes para o método da simulação. É possível, portanto, para cada situação, verificar os índices de desempenho do sistema, como a eficiência e o extravasamento.

Por fim, para o método proposto por Dornelles (2012), foram utilizadas as tabelas fornecidas e os valores foram interpolados para a adequação da situação do presente trabalho. Devido aos valores máximos fornecidos pelas tabelas dispostas em Dornelles (2012), o cálculo teve o objetivo de atender $70 \%$ e $80 \%$ da demanda para as cidades de Belo Horizonte e Goiânia. Já para cidade de Porto Alegre foi possível calcular $70 \%, 80 \%$ e $90 \%$ de atendimento à demanda. Verificou-se, também, os índices de desempenho para os volumes máximos possíveis do método para cada capital, ou seja, de $100 \mathrm{~L} / \mathrm{m}^{2}$, o equivalente a $15 \mathrm{~m}^{3}$, considerando que o cenário em questão é para a área de coleta de $150 \mathrm{~m}^{2}$. 


\section{RESULTADOS E DISCUSSÃO}

Com os dados de séries históricas de precipitação para as capitais Belo Horizonte, Goiânia e Porto Alegre foi possível analisar os índices pluviométricos de cada cidade durante o ano. As médias anuais de precipitação foram de 1558 mm, 1573,22 mm e 1427,29 mm para as capitais mineira, goiana e gaúcha, respectivamente. $\mathrm{Na}$ Figura 3, são apresentadas as médias mensais pluviométricas para as capitais.

Figura 3 - Distribuição pluviométrica mensal média para Belo Horizonte (MG), Goiânia (GO) e Porto Alegre (RS)

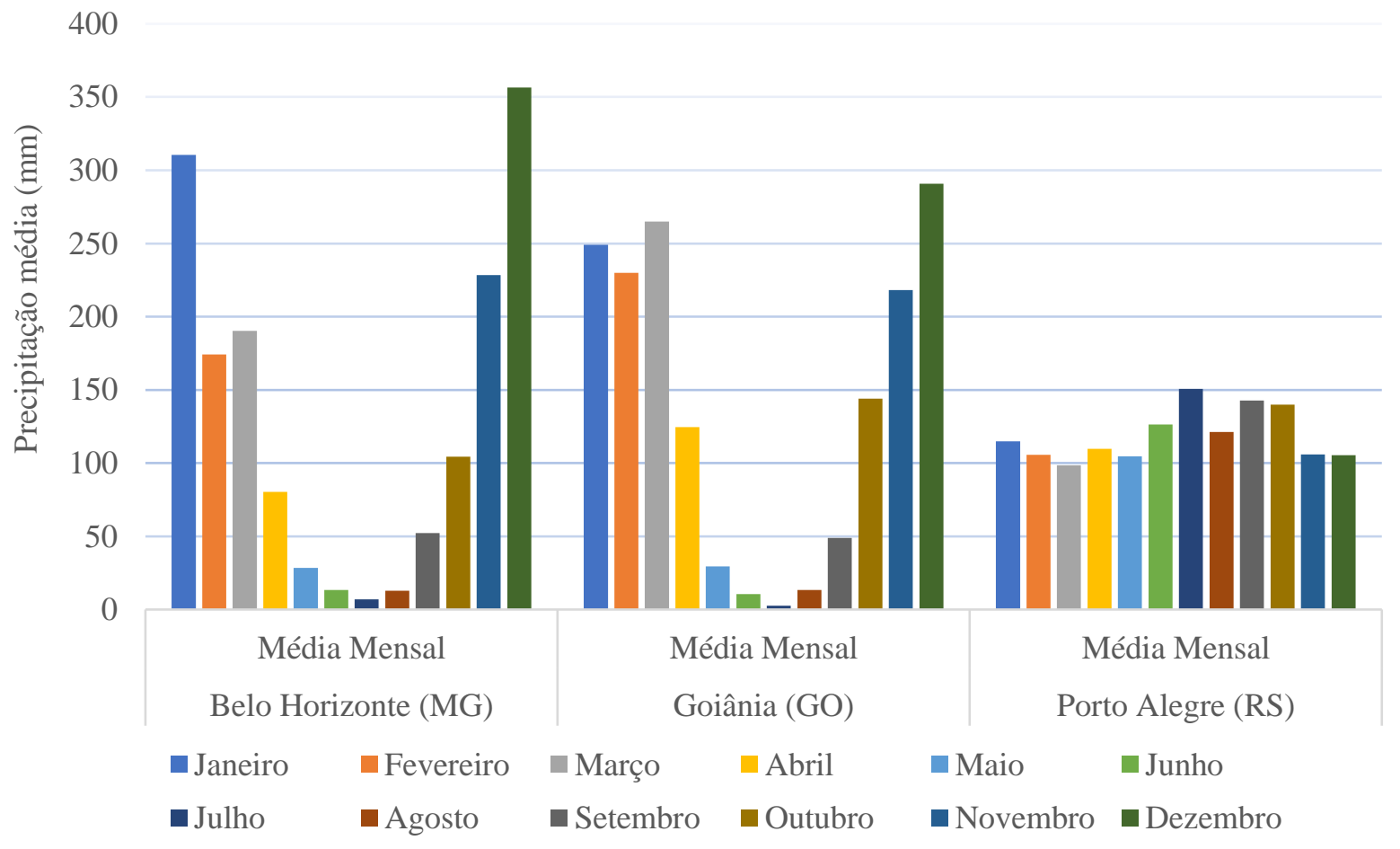

Fonte: Elaborado pelos autores

Observa-se, pela Figura 3, que em Belo Horizonte há a concentração da chuva entre os meses de novembro e janeiro, enquanto a época de chuvas para Goiânia é entre dezembro a março e, em Porto Alegre, as chuvas são bem distribuídas durante todo o ano, com níveis um pouco acima da média em julho, setembro e outubro.

Com base nos dados pluviométricos apresentados, foram realizados os cálculos dos volumes do reservatório para o SAAP, para os cenários descritos e métodos de norma; considerando-se para o método de Rippl tantos as médias diárias quanto as médias mensais pluviométricas. Os resultados dos métodos relatados podem ser vistos, de forma resumida, na Figura 4. 
Figura 4 - Gráfico comparativo entre métodos

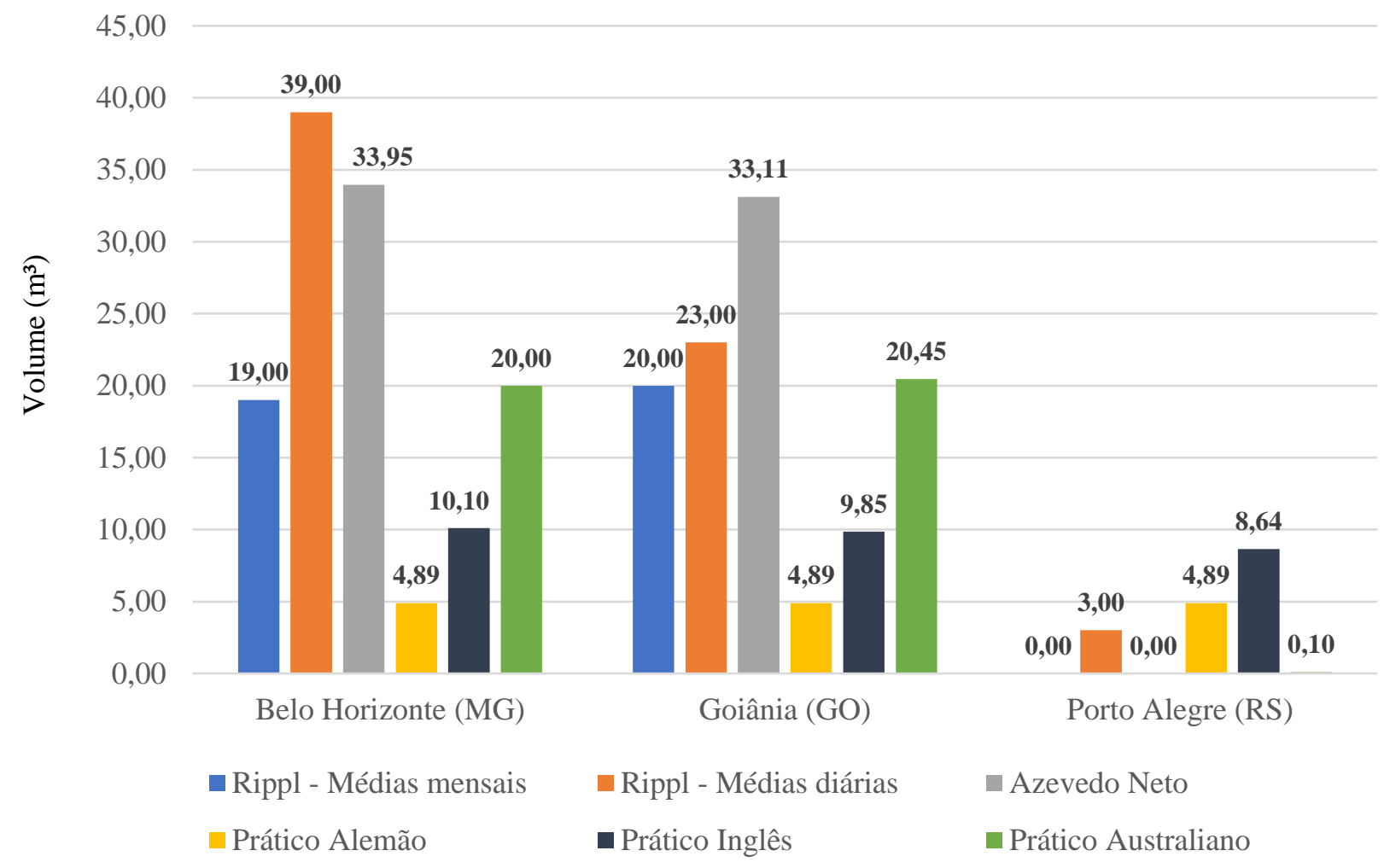

Fonte: Elaborado pelos autores

Nota-se que os resultados variam bastante entre si, o que pode causar dúvidas ao projetista em relação ao volume que deve ser adotado, como citado anteriormente. Com base nos valores encontrados foram arbitrados os volumes de reservatórios para utilização do método da simulação.

Os índices de desempenho obtidos são apresentados na Tabela 4, que apresenta o volume do reservatório, o nível de atendimento à demanda (e) e o extravasamento (Ex.).

Como mencionado, os cálculos foram efetuados conforme os valores máximos fornecidos nas tabelas propostas por Dornelles (2012), sendo de 70\% e 80\% para Belo Horizonte e Goiânia e 90\% para Porto Alegre. Também foram observados os índices de desempenho para o caso de um reservatório de $15 \mathrm{~m}^{3}$, o máximo fornecido nas tabelas. 
Tabela 4 - Resultados do Método da Simulação

\begin{tabular}{|c|c|c|c|c|c|c|c|c|}
\hline \multicolumn{3}{|c|}{ Belo Horizonte (MG) } & \multicolumn{3}{|c|}{ Goiânia (GO) } & \multicolumn{3}{|c|}{ Porto Alegre (RS) } \\
\hline $\begin{array}{l}\text { volume do } \\
\text { reservató- } \\
\text { rio }\left(\mathrm{m}^{3}\right)\end{array}$ & e (\%) & Ex (\%) & $\begin{array}{c}\text { volume do } \\
\text { reservatório } \\
\left(\mathrm{m}^{3}\right)\end{array}$ & e (\%) & Ex (\%) & $\begin{array}{c}\text { volume do } \\
\text { reservatório } \\
\left(\mathrm{m}^{3}\right)\end{array}$ & e (\%) & Ex (\%) \\
\hline 5,00 & $67,51 \%$ & $71,15 \%$ & 5,00 & $68,13 \%$ & $71,51 \%$ & 1,00 & $56,47 \%$ & $71,13 \%$ \\
\hline 10,00 & $74,71 \%$ & $68,10 \%$ & 10,00 & $74,73 \%$ & $68,83 \%$ & 3,00 & $83,86 \%$ & $59,25 \%$ \\
\hline 15,00 & $80,87 \%$ & $65,46 \%$ & 15,00 & $80,81 \%$ & $66,32 \%$ & 5,00 & $91,48 \%$ & $55,71 \%$ \\
\hline 20,00 & $86,97 \%$ & $62,82 \%$ & 20,00 & $86,89 \%$ & $63,81 \%$ & 10,00 & $97,57 \%$ & $53,12 \%$ \\
\hline 25,00 & $92,90 \%$ & $60,25 \%$ & 25,00 & $92,70 \%$ & $61,44 \%$ & 15,00 & $98,37 \%$ & $52,67 \%$ \\
\hline 30,00 & $97,29 \%$ & $58,38 \%$ & 30,00 & $97,03 \%$ & $59,59 \%$ & 20,00 & $98,65 \%$ & $52,45 \%$ \\
\hline 35,00 & $99,37 \%$ & $57,48 \%$ & 35,00 & $99,16 \%$ & $58,68 \%$ & 25,00 & $98,85 \%$ & $52,25 \%$ \\
\hline 40,00 & $99,93 \%$ & $57,17 \%$ & - & - & - & 30,00 & $99,05 \%$ & $52,06 \%$ \\
\hline
\end{tabular}

Fonte: Elaborado pelos autores

Os resultados para o método proposto por Dornelles podem ser observados por meio da Tabela 5.

Tabela 5 - Resultados do método proposto por Dornelles

\begin{tabular}{|c|c|c|c|c|c|c|c|c|}
\hline \multicolumn{3}{|c|}{ Belo Horizonte (MG) } & \multicolumn{3}{|c|}{ Goiânia (GO) } & \multicolumn{3}{|c|}{ Porto Alegre (RS) } \\
\hline $\begin{array}{c}\text { volume do } \\
\text { reservatório } \\
\left(\mathrm{m}^{3}\right)\end{array}$ & e (\%) & Ex. (\%) & $\begin{array}{c}\text { volume do } \\
\text { reservatório } \\
\left(\mathrm{m}^{3}\right)\end{array}$ & e (\%) & $\begin{array}{l}\text { Ex } \\
\text { (\%) }\end{array}$ & $\begin{array}{c}\text { volume do } \\
\text { reservatório } \\
\left(\mathrm{m}^{3}\right)\end{array}$ & $\begin{array}{c}\mathbf{e} \\
(\%)\end{array}$ & Ex. (\%) \\
\hline 3,06 & $70,00 \%$ & $61,08 \%$ & 3,13 & $70,00 \%$ & $60,95 \%$ & 1,03 & $70,00 \%$ & $58,55 \%$ \\
\hline 8,23 & $80,00 \%$ & $57,52 \%$ & 9,49 & $80,00 \%$ & $57,55 \%$ & 1,65 & $80,00 \%$ & $54,44 \%$ \\
\hline 15,00 & $87,80 \%$ & $54,80 \%$ & 15,00 & $87,00 \%$ & $55,20 \%$ & 2,95 & $90,00 \%$ & $50,04 \%$ \\
\hline- & - & - & - & - & - & 15,00 & $99,70 \%$ & $45,00 \%$ \\
\hline
\end{tabular}

Fonte: Elaborado pelos autores

De modo geral, os métodos de dimensionamento, tanto aqueles abordados na NBR 15527 (ABNT, 2007) e o método proposto por Dornelles, apresentaram valores semelhantes, com a mesma ordem de grandeza para Belo Horizonte e Goiânia, que possuem regimes de chuva e médias anuais semelhantes. Todavia, para Porto Alegre, os resultados foram muito baixos, devido ao fato de que a capital gaúcha possui um regime de chuvas bem distribuído durante 0 ano.

\section{CONCLUSÕES}

O referido trabalho comparou os volumes obtidos pelos métodos de dimensionamento de reservatórios para aproveitamento das águas pluviais; tomando-se como referência uma residência hipotética em três capitais brasileiras. 
De um modo geral, utilizando-se os métodos práticos, foi possível observar a discrepância entre os valores observados para os volumes calculados de reservatórios. Tal fato, pode inviabilizar a tomada de decisão pelo projetista, ressaltando, ainda, a limitação de tais métodos quanto ao desempenho do SAAP em seu tempo de uso. Na utilização do Método de Rippl, observou-se primeiramente, que os dados diários fornecem resultados de volumes maiores se comparados aos volumes obtidos utilizando-se os dados mensais. Nota-se que isto deve-se ao fato de que, quando os cálculos são realizados seguindo médias diárias, os períodos de seca são mais facilmente demonstrados que em médias mensais.

Ainda quanto ao Método de Rippl, especificamente, em relação às médias mensais de Porto Alegre, o volume do reservatório encontrado foi nulo. Isto se deve à grande diferença entre a demanda por água pluvial e o volume de chuva que é possível ser captado. Neste caso, é recomendável que seja utilizada uma área de coleta menor que $150 \mathrm{~m}^{2}$ ou, ainda, diminua-se o volume de água pluvial que será utilizado para suprir as demandas.

O Método Azevedo Neto forneceu volumes de reservatórios de 33,95 m³ 33,11 $\mathrm{m}^{3}$ e $0 \mathrm{~m}^{3}$ para Belo Horizonte, Goiânia e Porto Alegre, respectivamente. Foram utilizados 4 meses de seca (junho, julho, agosto e setembro) para as duas primeiras cidades e, para a capital gaúcha, utilizou-se nenhum mês de pouca chuva, tendo em vista que possui chuvas regulares durante todo $o$ ano. Tratando-se de residências familiares, percebe-se que os resultados para Belo Horizonte e Goiânia são muito altos e o espaço ocupado por reservatórios de volumes dessa grandeza pode ser um obstáculo.

Com o volume de 4,89 $\mathrm{m}^{3}$, o Método Prático Alemão propicia o mesmo valor para três cidades com regimes pluviométricos diferentes, baseando-se, somente, no consumo que será destinado a água captada das chuvas. Dependendo da necessidade do usuário, tal valor pode ser subestimado para Belo Horizonte e Goiânia, com eficiência pelo Método de Simulação abaixo de 70,00\%, e superestimado para Porto Alegre, com valor chegando a $90 \%$ de eficiência.

De forma semelhante, o Método Prático Inglês não apresentou valores com diferenças significativas entre as capitais, com 10,10 $\mathrm{m}^{3}, 9,85 \mathrm{~m}^{3}$ e 8,64 $\mathrm{m}^{3}$ para Belo Horizonte, Goiânia e Porto Alegre, respectivamente. O método fundamenta-se, somente, no valor da precipitação média anual sem contemplar as variações sazonais 
observadas entre as capitais. Fato este, que combinado às demandas que serão destinadas as águas de chuva, pode ocasionar em um projeto frustrante, dependendo da necessidade da família ou indivíduo residente no imóvel destinado ao aproveitamento das águas pluviais.

Tendo em vista os valores com $100,00 \%$ de confiança, como aborda a NBR 15527 (ABNT, 2007), o Método Prático Australiano ofereceu volumes para Belo Horizonte, Goiânia e Porto Alegre de 20,00 m³, 20,45 $\mathrm{m}^{3}$ e 0,1 $\mathrm{m}^{3}$. De forma semelhante ao Método de Rippl, o Método Prático Australiano efetua o balanço mensal entre o volume de chuva que é possível de ser armazenado e a demanda. Em Porto Alegre o volume de chuva gerado é muito superior que a demanda e, por esse motivo, resulta em um valor próximo de zero. Isto pode ser entendido como inutilidade de reserva, pois, o que chove seria, simultaneamente, destinado ao uso.

Recomenda-se, como realizado neste trabalho, que os valores obtidos nos métodos práticos e de Rippl sirvam de base para a estimativa inicial a ser utilizada no Método da Simulação e, assim, analisar o real desempenho do reservatório dimensionado. Tal metodologia, apesar de dispender grande tempo, fornece resultados mais seguros e confiáveis.

Comparando-se o Método de Simulação com o proposto por Dornelles (2012), pela utilização de ábacos e tabelas, este denota simplicidade de utilização, já que não é necessário a obtenção de séries históricas ou cálculos rebuscados; mostrando-se simples e objetivo.

Os resultados, comparados, com o Método da Simulação possuem certas diferenças, tendo em vista os índices de desempenho, que, todavia, ainda são confiáveis. O valor de 15,00 $\mathrm{m}^{3}$, destacado na Tabela 4 para o Método de Simulação, retrata uma eficiência de $80,87 \%, 80,81 \%$ e $98,37 \%$, enquanto que para o método proposto por Dornelles (2012), destacado na Tabela 5, 87,80\%, 87,00\% e 99,70\%, para Belo Horizonte, Goiânia e Porto Alegre, respectivamente. As diferenças percentuais são, aproximadamente, de 7,00\% para as duas primeiras cidades e 1,00\% para a última. Note que os dois métodos podem ser utilizados com segurança, sendo o de Dornelles (2012) mais simples para as capitais.

Por fim, de posse dos índices de desempenho para diferentes volumes de reservatório, é possível que o projetista decida qual será utilizado, baseando-se na necessidade do indivíduo ou família e o investimento que poderá ser dedicado à implantação do SAAP. 


\section{REFERÊNCIAS}

AMORIM, S. V.; PEREIRA, D. J. A. Estudo comparativo dos métodos de dimensionamento para reservatórios utilizados em aproveitamento de água pluvial. Revista Ambiente Construído. Porto Alegre, v. 8, n. 2, p.53 - 66, abr./jun. 2008,

ASSOCIAÇÃO BRASILEIRA DE NORMAS TÉCNICAS. NBR 15527: Água de chuva - aproveitamento de coberturas em áreas urbanas para fins não potáveis - requisitos. Rio de Janeiro, 2007. 08p.

AZEVEDO NETTO, J. M; FERNANDEZ, M. F; ARAUJO, R.; ITO, A. E. Manual de Hidráulica. 8. ed. São Paul, SP, 1998. 669 p.

CARVALHO, G. S.; OLIVEIRA, S. C.; MORUZZI, R. B. Cálculo do volume do reservatório de sistemas de aproveitamento de água de chuva: Comparação entre métodos para aplicação em residência unifamiliar. X Simpósio Nacional de Sistemas Prediais. 2007. 10 p.

COHIM, E.; GARCIA, A.; KIPERSTOK, A. Captação e aproveitamento de água de chuva: dimensionamento de reservatórios. In: SIMPÓSIO DE RECURSOS HÍDRICOS DO NORDESTE, 10., 2008. Anais.... 2008. 16 p.

CUBA, R. M. F., MANZANO D. P. Avaliação técnica e econômica do reúso de águas cinza em aparelhos sanitários. Colloquium Exactarum, Presidente Prudente, set.-out. 2014, v. 6, n. 3 , p. $72-83$.

CUNHA, A. H. N.; OLIVEIRA, T. H. de; FERREIRA, R. B.; MILHARDES, A. L. M.; SILVA, S. $M$. da $\mathrm{C}$ e. O reúso de água no Brasil: a importância da reutilização de água no país. Enciclopédia livre, Goiânia, 2011, v. 7, n. 13, p. 1225 - 1248.

DANTAS, D. L.; SALES, A. W. C. Aspectos ambientais, sociais e jurídicos do reúso da água. Revista de Gestão Social e Ambiental, São Paulo, v. 3, n. 3, p. 4 - 19, set./dez. 2009.

DISTEFANO, T.; KELLY S. Are we in deep water? Water scarcity and its limits to economic grownth. Ecological Economics, v. 142, p. 130 - 147, dez. 2017. Disponível em: goo.gl/4dqqbi. Acesso em: 23 nov. 2018.

DORNELLES, F. Aproveitamento de água de chuva no meio urbano e seu efeito na drenagem pluvial. Tese (Doutorado) - Universidade Federal do Rio Grande do Sul. Instituto de Pesquisas Hidráulicas. Porto Alegre - RS, 2012. 219 p.

ELIASSON, J. The rising pressure of global shortages. Nature, v. 517, p. 6, jan. 2015, Disponível em: goo.gl/KtU8V2. Acesso em: 23 nov. 2018.

FONSECA, V. L. A.; NASCENTES, R.; CAIXETA, L. T. Técnicas de baixo custo para aproveitamento de água de chuva e reúso de água cinza: o início de uma cultura de conservação da água em Rio Paranaíba-MG. Revista ELO, Viçosa, v. 07, n. 1, p. 28 - 38, jun. 2018,

GIACCHINI, M. O método de Rippl para dimensionamento de reservatório de sistemas de aproveitamento da água de chuva. In: CONGRESSO TÉCNICO CIENTÍFICO DA ENGENHARIA E DA AGRONOMIA. Anais... Foz do Iguaçu, 2016.

HESPANHOL, I. Possibilidades de reúso de água no brasil: Agricultura, Indústria, Municípios, Recarga de Aquíferos. Revista Brasileira de Recursos Hídricos, p. 75 - 95, out./dez. 2002. 
INSTITUTO DE PESQUISAS TECNOLÓGICAS - IPT. Captação de água de chuva. 2016. Disponível em: goo.gl/GR48JT. Acesso em: 02 dez. 2018.

LEITE, B. L. F. Avaliação econômica da implementação de sistema de aproveitamento de águas pluviais em empreendimento "minha casa, minha vida" em Porto Alegre. Trabalho de Conclusão de Curso (Graduação) - Universidade Federal do Rio Grande do Sul. Departamento de Engenharia Civil. Porto Alegre, 2017. 94 p.

MAY, S. Caracterização, tratamento e reúso de águas cinza e aproveitamento de águas pluviais em edificações. Tese (Doutorado) - Escola Politécnica da Universidade de São Paulo. Departamento de Engenharia Hidráulica e Sanitária. São Paulo, 2009. 222 p.

MORUZZI, R. B.; OLIVEIRA, S. C. Aplicação de programa computacional no dimensionamento de volume de reservatório para sistema de aproveitamento de água pluvial na cidade de Ponta Grossa, PR. Revista de Engenharia e Tecnologia, v. 2, n. 1, p. 36 - 48, abr. 2010.

MUNHOZ, F.D. Reúso de água em residências de pequeno e médio porte com sistema pré-fabricado. Trabalho de Conclusão de Curso (Graduação)- Universidade Anhembi Morumbi. São Paulo, 2006. 46 p.

NOVAKOSKI, C. K.; MARQUES, M. G.; CONTERATO, E. Análise do método da simulação para dimensionamento de reservatórios de águas pluviais em residências unifamiliares. In: SIMPÓSIO BRASILEIRO DE RECURSOS HIDRICOS. Anais... Bento Gonçalves (RS), 2013. 8 p.

ONU Brasil. Até 2030 planeta pode enfrentar déficit de água de até $40 \%$, alerta relatório da ONU. 2015. Disponível em: goo.gl/R2Dhm>. Acesso em: 01 maio 2018.

TOMAZ, P. Aproveitamento de água de chuva em áreas urbanas para fins não potáveis. 2010. Disponível em: goo.gl/7z2j49. Acesso em: 17 set. 2018.

WANJIRU, E.; XIA, X. Sustainable energy-water management for residential houses with optimal integrated grey and rain water recycling. Journal of Cleaner Production, v. 170, p. 1151 - 1166, jan. 2018. Disponível em: goo.gl/6yMycY. Acesso em: 24 out. 2018. 